\title{
FUTURE OF BITUMEN EMULSION AS AN ENVIORNMENTAL FRIENDLY ROAD CONSTRUCTION MATERIAL
}

\author{
H.L.D.M.A. Jud th \& J.M.S.J. Bandara \\ Department of Civil Engineering, University of Moratuwa.
}

Bitumen emulsion is a thermodynamically unstable heterogeneous system in which finely ground bitumen particles are dispersed in an aqueous medium. In most parts of the world usage of bitumen emulsion as a road construction material has increased during the recent past partially replacing penetration grade bitumen (tar) and cutback bitumen due to environmental reasons. In Sri Lanka bitumen emulsion is used for certain road construction work. However, still there is somewhat reluctance among road engineers to use bitumen emulsion as a substitute for other types

There are numerous uses for bitumen emulsion utilizing highly varied techniques, which results in several different formulations; namely cationic and anionic depending on particle charges and rapid setting, medium setting and slow setting depending on its spced of separation of bitumen from aqueous mediunt. In Sri Lanka, cationic type bitumen emulsion is used, as majority of the available local aggregates are acidic except Jaffna limestone.

Bitumen emulsion is suitable to the requirements of all road maintenance work. Ease of storage and transport make it possible to set up numerous depots and its case and facility of use enatle work to be done quickly causing minimum disturbance to the users. It may be the first choice bituminous material for all maintenance work on road pavements duc to environmental friendliness, provided that correct proportions and standard specifications are being used

Bitumen emulsion has proven itself à a binder, which utilises very low energy consumption in road maintenance and laving of surface dressings. Penetration grade bitumen requires heating at construction sites, which emit smoke with chemicals and also it needs fuel, which is a non-renewable resource. Kerosene that is used for cutting back the viscosity of bitumen is also a non-recoverable waste when curing takes place on the road

This paper identifies the advantages of using bitumen emulsion over other traditional altcrnatives and investigates the reasons for the reluctance to use locally. The paper proposes suitable remedial measures to overcome the perceived disadvantages and increase the use of bitumen emulsion as an environment friendly alternative

Proceedings of the Eighth Annual Forestry and Environment Symposium 2002 of the Department of Forestry and Environmental Science, Uiversity of Sri Jayewardenepura, Sri Lanka 